\title{
Vigilância, controle e atenção: a desinformação como estratégia
}

Surveillance, control and attention: disinformation as a strategy

Vigilancia, control y atención: la desinformación como estrategia

- Tem pós-doutorado em Comunicação e Cultura pela Escola de Comunicação da Universidade Federal do Rio de Janeiro (ECO-UFRJ).

- Doutora em Processos Comunicacionais pela Universidade Metodista de São Paulo (Umesp).

- Mestra em Comunicação e Cultura pela ECO-UFRJ.

- Bacharel em Jornalismo pela Universidade Federal do Piauí (UFPI).

- Professora do Programa de Pós Graduação da UFPI.

- Coordenadora da Rede Nacional de Combate à Desinformação (RNCD-Brasil).

- E-mail: anareginarego@gmail.com 


\section{Resumo}

Este ensaio de cunho teórico foi construído no intuito de tensionar o debate sobre a desinformação procurando trazer para a visibilidade aspectos mais amplos e que se inserem silenciosamente em nosso contexto social nos dias atuais. Partimos de uma visada situada entre Foucault e Deleuze sobre vigilância e controle, passamos rapidamente pela economia da atenção e problematizamos as reações que podem irromper a partir da sinergia entre ações despertadas por uma consciência histórica.

\section{PALAVRAS-CHAVE: VIGILÂNCIA •CONTROLE •RESISTÊNCIA・DESINFORMAÇÃO・RNCD}

\section{Abstract}

Our theoretical essay aims at tensioning the debate about disinformation, seeking to give visibility wider aspects that are silently inserted in our social context. We started from a view located between Foucault and Deleuze on surveillance and control, then quickly went through the economy of attention and problematized the reactions that can emerge from the synergy among actions awakened by a historical conscience.

\section{KEYWORDS: SURVEILLANCE・CONTROL・RESISTANCE・DISINFORMATION・RNCD}

\section{Resumen}

Este ensayo teórico tuvo como objetivo debatir sobre la desinformación, buscando sacar a la luz aspectos más amplios que se insertan silenciosamente en nuestro contexto social actual. Partimos de la perspectiva entre Foucault y Deleuze sobre vigilancia y control, pasamos brevemente por la economía de la atención y problematizamos las reacciones que pueden surgir de la sinergia entre acciones despertadas por una conciencia histórica. 


\section{INTRODUÇÃO}

O Panóptico não é uma prisão. É um princípio geral de construção, o dispositivo polivalente da vigilância, a máquina óptica universal das concentrações humanas.

Jeremy Bentham, 2019, p.89.

A desinformação tem dominado o debate neste 2020 conturbado e marcado pela pandemia da Covid-19 que, nos últimos dias de outubro, momento em que escrevo o presente texto, ultrapassa a casa de 1 milhão e duzentos mil mortos em todo o mundo. Nesse caos desinformativo, a polêmica situa-se em torno do confronto entre as conceituações plausíveis e capazes de conformar o fenômeno, que em si e a partir da visada fenomenológica que adotamos, seria principalmente 0 lado oposto da informação e que por esta se faz passar de forma contumaz.

A desinfopandemia (Bontcheva; Posetti, 2020) ou infopandemia tem sido apontada como a grande causadora da instalação da cultura do ódio nas sociedades contemporâneas, do desentendimento político na maioria dos países ocidentais, pelo medo, pela angústia, como ainda pela propagação de uma fé fundamentalista. 0 ambiente político também tem sido agente e vítima da pandemia da desinformação e, por último, a própria pandemia da Covid-19 tem se tornado terreno fértil para o incremento produtivo das fábricas de desinformação, mas também para produção e circulação de narrativas desinformacionais a partir de ambientes sociais engajados como a classe médica, em que alguns atores se colocam em confronto com a ciência, expondo tensões entre os regimes de verdade de experiência e evidência (Rêgo; Leal, 2020).

Todavia, há que se ponderar que a desinformação potencializada atualmente pela sociedade tecnológica que nos permite e nos exige uma biosvirtual (Sodré, 2002), tem provocado o incremento de um fenômeno social de grandes dimensões, que apesar de holístico, é, principalmente, uma estratégia' que envolve fenômenos bem mais complexos que hoje nos perpassam silenciosamente e que, sem nos darmos conta, já estão nos controlando por diversos meios.

Como no cenário de um mágico em uma apresentação pública, tudo que é preparado para a visibilidade se coloca sobre os holofotes e tem a intencionalidade de ocultar o que ocorre atrás das cortinas. A desinformação que concorre com sua parte essencial, a informação, surge neste contexto, como sombra e luz, ora enganando, ora sendo revelada, após cumprir com seus objetivos.

As estruturas de poder - neste momento histórico com preponderância das estruturas de poder econômico sobre as de poder político - criam estratégias e distrações com potencial duplamente lucrativo, cujos meandros finais são permeados por caminhos díspares que envolvem desregulamentação do direito universal, alianças entre tecnologia e psicologia, modelos de negócios que visam monopólios, tornando a livre-concorrência tão somente uma velha e esquecida retórica vendida pelo liberalismo e por sua versão mais perversa, o neoliberalismo. 0 mercado da desinformação ou, como denominamos em outro estudo, o mercado da construção intencional da ignorância é tão somente uma das estratégias, mas é forte o suficiente para inspirar a sociedade a entrar no jogo de construção diária de desinformação, conformando, como dito, um fenômeno social de grandes dimensões.

Neste texto, trabalhamos um pouco no revelar de outros fenômenos que permitem que a desinformação, enquanto fenômeno coletivo vinculado à informação, exista e persista no seio de nossa sociedade, para tanto, retornamos a Foucault, Deleuze,

1 Estratégia, na concepção de Hamel e Prahalad (1995), em que uma intenção estratégica desenvolvida a partir de competências essenciais e inserida em uma arquitetura estratégica de modo sinérgico, termina por guiar as ações das empresas rumo ao futuro das organizações. Veremos que dentro das grandes empresas digitais tal conceito foi adaptado ao modelo de negócios que prevê crescimento constante e ininterrupto, mas que nem sempre preza pela ética empresarial. 
Simon e Bourdieu com o intuito de problematizar o contexto e situar, ao final, os movimentos de resistência ao fenômeno por nós aqui privilegiado.

\section{A VIGILÂNCIA, O CONTROLE E O JULGAMENTO}

Nas sociedades disciplinares detalhadas por Foucault ${ }^{2}(1999,2002)$ a vigilância é mimética e simbolicamente representada pela projeção do panóptico de Bentham, que, conforme o próprio Bentham, no trecho que abre o presente ensaio, extrapola o edifício e se constitui como um dispositivo onipresente que permite ao poder disciplinar tornar-se sistêmico e integrado, interligando o dispositivo de vigilância às intenções do mercado em que o mesmo estava instalado.

Organiza-se assim como um poder múltiplo, automático e anônimo: pois, se é verdade que a vigilância repousa sobre os indivíduos, seu funcionamento é de uma rede de relações de alto a baixo, mas também até certo ponto de baixo para cima e lateralmente: essa rede "sustenta" o conjunto, e o perpassa de efeitos de poder que se apoiam uns sobre os outros: fiscais permanentemente fiscalizados. (Foucault, 2008, p.148)

Foucault alerta para o fato de que a hierarquização da vigilância termina por se constituir como uma máquina, fazendo com que o aparelho de vigilância inteiro produza mais e mais poder, distribuindo os indivíduos pelo sistema de modo permanente.

A vigilância tornava o poder disciplinar, ao mesmo tempo, indiscreto já que se colocava como ubíquo e alerta procurando controlar indivíduos e fiscais do sistema, mas também discreto, visto que funcionava silenciosamente.

Para Foucault, a disciplina enquanto parte do sistema de poder colocava em funcionamento um tipo de poder relacional que teria uma sustentabilidade própria, calcada na fiscalização permanente entre os membros vigiados e vigilantes. "Graças às técnicas de vigilância, a "física" do poder, o domínio sobre o corpo se efetua segundo as leis da ótica e da mecânica, segundo um jogo de espaços, de linhas, de telas, de feixes, de graus e sem recurso, pelo menos em princípio, ao excesso, à força, à violência" (Foucault, 2002, p.148).

A vigilância na sociedade disciplinar, tanto quanto na posterior e diversa sociedade do controle, tem o intuito de produzir informações sobre os vigiados. Como nos diz Foucault ao tratar do panoptismo, a vigilância tem como vínculos de apoio um sistema de registro permanente de informações, relatórios que circulam entre as instâncias de poder social e político no contexto da modernidade. Os espaços de vigilância tornam-se crescentes e se inserem diretamente nos aparelhos do poder que perpassam estruturas de dominação, para além das prisões, dos manicômios, das universidades, os aparelhos passam a controlar a sociedade a partir de seus registros de nascimento e morte, cadastros de contribuintes, informações financeiras etc.

A representação do panóptico permite visualizar a estruturação da vigilância de modo real e metafórico, como permeada por um espaço

[...] fechado, recortado, vigiado em todos os seus pontos, onde os indivíduos estão inseridos num lugar fixo, onde os menores movimentos são controlados, onde todos os acontecimentos são registrados, onde um trabalho ininterrupto de escrita se liga ao centro e periferia, onde o poder é exercido sem divisão, segundo uma figura hierárquica contínua, onde cada indivíduo é constantemente localizado, examinado e distribuído entre os vivos, os doentes e os mortos, isso tudo constitui um modelo compacto do dispositivo disciplinar. (Foucault, 2002, p.163)

2 Em Vigiar e punir (2002), Foucault, ao tratar da sociedade e do poder disciplinar da Modernidade, apresenta os dispositivos e mecanismos de vigilância. 
O panoptismo e seu dispositivo de vigilância máxima, o panóptico, se configuram como representações importantes na análise foucaultiana da sociedade e do poder disciplinar, uma vez que permitem automatizar e pluralizar o poder. Situando a vigilância e o poder, não em um ser individual, mas em uma rede de distribuição que se compõe de corpos, luzes, olhares, aparelhos etc. "Há uma maquinaria que assegura a dissimetria, o desequilíbrio, a diferença. Pouco importa, consequentemente, quem exerce o poder". A ideia do Panóptico parece assim, para Foucault, um dispositivo esplêndido que, "[...] a partir dos desejos mais diversos, fabrica efeitos homogêneos de poder" (Foucault, 2002, p.167).

Na sociedade disciplinar instalada no regime de historicidade da modernidade, a informação ganha importância com 0 avançar das tecnologias da comunicação e informação e, portanto, passa a ocupar papel central na ordem e disciplina, logo, a vigilância permanente que permite também a coleta de informações torna-se parceira constante. Distintas, múltiplas e entrecruzadas formas de vigilância convivem e se alternam no contexto social, mas dependem de uma hierarquização entre os indivíduos que possa definir vigilantes e vigiados, sendo os vigilantes, em algum grau, também vigiados, conformando um modelo piramidal que permite a estruturação de uma grande rede de poder com o intuito de controlar e manter o exercício do poder que, na visão foucaultiana, não se detém nem se transfere, mas tão somente se exerce a partir das estruturações tensionais que se estabelecem no contexto social.

Veremos que, conforme Deleuze (1992), a sociedade disciplinar termina por ceder lugar a uma sociedade do controle, contudo, vale ponderar que algumas das revelações feitas por Foucault e por nós apontadas acima podem também nos permitir uma visada mais ampla sobre os fenômenos que hoje vivenciamos.

Segundo Bruno (2008, p.167-170), a vigilância digital já está inserida entre nós há algumas décadas e se concentra em filtrar três principais agentes constitutivos e interagentes no cenário econômico, que seriam: informações, dados e perfis, através de um monitoramento sistemático de nossas atividades no mundo virtual. A vigilância digital permanente garimpa nossos dados e constrói infinitos bancos de dados, e, por último, os perfis computacionais que possibilitam a transformação dos dados em conhecimento, trabalhando processos de individualização.

Para Abramovay (2019), a vigilância digital é a principal característica da sociedade atual, tendo se transformado em uma decisiva estratégia que interfere em nossas sociabilidades e afetividades, visto que a manipulação psicológica que sofremos nos agrupa em bolhas de pensamentos similares e nos faz rejeitar pensamentos opostos aos nossos, fomentando em muitos casos o ódio e instalando o medo. Para este professor da Universidade de São Paulo a vigilância ocupa hoje o core business das plataformas digitais e não se restringe à garimpagem que realizam nos dispositivos que atuam sobre nós e nossas vidas, mas, como pontuamos acima, influi diretamente na interferência psicológica das redes em nossas vidas.

\footnotetext{
"Compartilhamento" é a forma adocicada de sua apresentação pública. Os 510 mil comentários e as 136 mil fotos postadas no Facebook por minuto, as 40 mil buscas no Google por segundo (1,2 trilhão em 2018) ou os 60 milhões de fotos que sobem ao Instagram todos os dias nos perfis de seus 500 milhões de usuários diários são a matéria-prima da mais importante inovação tecnológica do século XXI: a inteligência artificial. (Abramovay, 2019)
}

De acordo com Tristan Harris, ex-especialista em ética do design do Google, no documentário da Netflix 0 dilema das redes (Orlowsky, 2020), as gigantes da tecnologia digital não utilizam a vigilância somente para garimpar informações e vendê-las aos anunciantes, o que também é feito, mas fazem experimentos diários e constantes, situando seus usuários em uma matrix em que, aos modos das irmãs Wachowsky (1999), inspiradas por Baudrillard (2014), realizam experimentos psicológicos com 0 intuito de promover mudanças comportamentais que possam favorecer seus negócios e seus lucros, através de parcerias entre uma tecnologia persuasiva e uma psicologia do reforço intermitente positivo, estimulados internamente dentro das empresas de tecnologia por um modelo de gestão conhecido como growth hacking, que se pauta no crescimento constante e ininterrupto. 
Em Deleuze, a sociedade do controle teria nascido nas últimas décadas do século XX e seria marcada por uma crescente intromissão das instituições estruturais da sociedade na vida cotidiana dos cidadãos. Uma sociedade sem limites definidos, composta por redes que se interconectam de forma crescente e possuidora de uma potencial centralidade na vida das pessoas, passa a regular as camadas sociais a partir do Estado ou do mercado.

Deleuze $(1990,1992)$ nos apresenta ao novo fenômeno social, a sociedade do controle, que teria manifestado mecanismos de vigilância e controle que extrapolariam o escopo das sociedades disciplinares como analisadas por Foucault. A sociedade do controle seria produto de uma transposição do mundo moderno como vivenciado nos últimos séculos e suas crises externadas nas últimas décadas do século XX. Uma de suas principais características seria a invasão permanente dos mecanismos do Estado e do mercado na vida privada dos cidadãos.

Na sociedade do controle as redes potencializam-se, interconectando mundo real e virtual numa simbiose indistinta e com capacidade para envolver os usuários de forma ubíqua tornando cada um de nós refém de seus mecanismos (Barbosa; Rêgo, 2020).

Nas sociedades do controle a senha passa a ser o passaporte e a identidade de cada pessoa para o mercado informacional e, como afirmam Rêgo e Barbosa (2020), essa nova conformação social estruturada em um poder ubíquo e silencioso, que se põe como gratuito e permite que se realizem inúmeras coisas boas para o conjunto da humanidade, é marcada, sobretudo, pela desconstrução do sujeito e sua mutação para o formato de dados, facilmente transformável em produto no e-commerce.

Nesse ínterim, vigilância e controle se aliam ao julgamento, fazendo dos usuários das redes sociais, já vigiados e vigilantes, também julgados e juízes, como parte essencial da manutenção do sistema mercadológico em que nos inserimos como produtores voluntários e produtos pluridimensionais. A sociedade do julgamento encontra-se nesse processo incrementada em relação ao ambiente analisado por Bourdieu (2008), o julgar enquanto atividade do espírito (Arendt, 2016) foi rebaixado a um comando mercadológico em busca de credibilidade para marcas pessoais que somos e que julgam e são julgadas por marcas empresariais. Julgamos o atendimento e a comida dos restaurantes, com estrelas nos aplicativos, que nos oferecem a oportunidade de ganhar pontos junto aos nossos seguidores e também frente à empresa que estamos credibilizando. Julgamos o motorista do Uber. Julgamos a foto dos amigos e dos inimigos, com curtidas ou com silêncio, porque assim, aparecemos mais e nos colocamos disponíveis para o julgamento coletivo. Em geral, julgamos positivamente para que assim sejamos julgados.

Vale ponderar que essa sociedade do julgamento, cujas características foram apropriadas e potencializadas pelo mercado, sobretudo pelas plataformas digitais e empresas do e-commerce, ganhou já há alguns anos um grande aliado, 0 algoritmo, cuja funcionalidade é guiar nosso olhar e direcionar tanto experiências que nos sejam mais favoráveis, quanto produtos. Se há cerca de dez anos as empresas de publicidade começaram a perceber que a visibilidade de seus clientes tinha sido reduzida a $10 \%$ da capacidade potencial que as redes sociais ofereciam antes, determinando a via do pagamento como 0 principal caminho para a projeção e reflexividade no ambiente virtual, para o caminho da visibilidade; inclusive, com formas de pagamento variadas e casadas entre si, com a concretização de relações comerciais, interesses em bancos de dados e pagamento em cash. Mais recentemente, a economia virtual do algoritmo tem mudado o dia a dia da linha do tempo dos nossos perfis nas redes sociais, procurando oferecer uma experiência agradável, eliminando, por exemplo, as diferenças de opinião e ideológicas.

Algoritmos são grupos de dados concatenados em normas organizacionais de informações sobre os usuários da internet, colhidos em diversas plataformas e a cada passo que damos no ambiente virtual. Esses dados com informações pessoais, mas também com o perfil dos nossos gostos, preferências, ideologias, práticas políticas, militâncias sociais etc. são utilizadas pelas plataformas digitais. 
O fenômeno então se revela como agradável ao usuário e facilitador de nossas vidas, pois nos oferece o livro ou a roupa que desejamos adquirir, ou nos mostra um artigo de alguém que pensa de forma parecida com a nossa. Todavia, nos impõe uma vida on-line permanente, onde nos mostramos e abrimos mão de nosso direito à privacidade, fornecendo não apenas dados pessoais e bancários, mas também nos revelamos em essência, como pessoas voltadas para determinadas causas estruturadas em determinados pensamentos.

Contudo, essa facilitação das vidas e esse ganho em visibilidade nos transforma em trabalhadores constantes no espaço midiático. Nos obriga a julgar os outros para sermos julgados positivamente e assim nos mantermos visíveis, pois somente desse modo nossa existência ganha em sentido. 0 objetivo das empresas além dos ganhos financeiros através das relações de poder no mercado midiático on-line e empresarial, é fazer com que continuemos a fornecer nosso tempo gratuitamente alimentando de informações de modo incessante as estruturas midiáticas que disponibilizam em "nosso favor". Quanto mais tempo ficamos on-line e quanto mais trabalhamos de graça, mais conteúdo produzimos e mais informações pessoais disponibilizamos e estas são armazenadas, analisadas e circulam e, principalmente, são negociadas.

0 mercado virtual ganha triplamente, enquanto nós, escravos de nossa vaidade, seguidores de Narciso, seguimos inertes rumo ao lugar do não pensamento. Nossa experiência que se torna positiva e agradável é, em verdade, um grande viés para a lucratividade mercadológica e tem como pressuposto o julgamento e a fidelidade. Para ser visível e bem julgado preciso me manter ativo postando, curtindo e compartilhando, enfim, somente sendo fiel poderei vir a ser, teoricamente, bem recompensado.

Mas o algoritmo que compõe o centro da vigilância, do controle e do julgamento também provoca o apartheid social em outro patamar, o da manipulação dos pensamentos, visto que passamos a receber somente informações e pensamentos ideológicos que são próximos aos nossos e que vão sendo aprofundados a cada nova mensagem recebida, tentando nos convencer a cada nova informação, sobre um modelo de vida e de estado das coisas que passamos a concordar, sobretudo, porque não temos acesso às ponderações e opiniões contrárias.

É nesse contexto que o algoritmo também se mostra primordial para o próximo fenômeno aqui abordado, a monetização da atenção.

\section{ECONOMIA DA ATENÇÃO}

0 pensamento de Simon (1979) do final da década de 1970 parece ser o ponto inicial para a compreensão de um processo econômico que se potencializaria a posteriori, com a venda da atenção das audiências. Para Simon, a abundância de informações, sua super oferta, provocaria a escassez de algo não tão valorizado até então, que seria exatamente a possibilidade de sua concretização existencial, a partir de um consumo final, somente operado pela atenção do cidadão que necessite da informação, ou que por ela se interesse. "Assim, uma riqueza de informação cria uma pobreza de atenção e a necessidade de alocar a atenção eficientemente entre uma superabundância de fontes de informação que pode consumi-la" (Simon,1979, p.498).

No contexto supra descrito, os grandes conglomerados digitais disputam de um lado o mercado de anunciantes publicitários que compõem inúmeros mercados tangíveis e intangíveis, mas com intuito de vender o sucesso para seus anunciantes, e disputam um outro mercado que é o da atenção de seus usuários, vendidos duplamente como produtos, como dito. De um lado, pelo despertar e pela manutenção permanente da atenção através das estratégias acima mencionadas, que passam pela mudança comportamental dos usuários e pelo domínio completo de nossa percepção por parte das empresas que, deste modo, comandam nossa atenção. Em outra visada, também somos vendidos como dados informacionais, não somente financeiros, mas também psicológicos e, por fim, somos consumidores viciados de um sistema que termina decidindo por nós. 
Conforme relatam Tristan Harris, ex-executivo da Google, Alex Roetter, ex-vice presidente do Twitter, Chamath Palihapitiva, ex-diretor de crescimento do Facebook, Tim Kendall, ex-diretor de monetização do Facebook, Guillaume Chaslot, diretor de algoritmos do YouTube, todos no documentário $O$ dilema das redes, em distintas palavras, mas de um modo convergente: as plataformas digitais que nos permitem uma biosvitual holística trabalham diuturnamente disputando entre si, nossa atenção, que é também, como dito acima, o principal produto vendido a seus clientes, os anunciantes.

A criação de algoritmos específicos para cada produto a nós ofertado tem não somente a intencionalidade de nos vender tais produtos que podem ser criações das próprias plataformas oferecidos aos usuários gratuitamente, mas, principalmente, de prender nossa atenção para garantir a venda dos produtos dos anunciantes.

Para Foer (2018) esse projeto mercadológico monopolista dos pontos de vista econômico, político e da atenção, esconde também um projeto ainda maior de dominação da humanidade a partir dos ideais megalomaníacos dos criadores e proprietários das gigantes da tecnologia digital, tais como Larry Page, do Google, que pretende criar máquinas que não somente repliquem 0 cérebro humano, mas que o ultrapassem, e Mark Zuckerberg, que segundo Foer trabalha arduamente para intervir no livrearbítrio dos usuários de suas redes sociais.

Sobre o Google, Foer (2018, p.43) afirma "O Google usa algoritmos treinados para pensar como nós, humanos. Para realizar uma tarefa tão assombrosa, a empresa precisa entender as intenções por trás de nossas pesquisas [...]". Já acerca do Facebook, Foer é bem direto

A verdade é que o Facebook é um emaranhado de regras e procedimentos para selecionar informações e essas regras são desenvolvidas pela empresa, para benefício final da empresa. Ela está o tempo todo vigiando os usuários, sempre auditando o que estão fazendo e usando-os como ratos de laboratório em seus experimentos comportamentais. Embora dê a impressão de que oferece escolhas, o Facebook de forma paternalista empurra os usuários na direção que considera melhor para eles, que não por acaso costuma ser a direção que os torna completamente dependentes. (Foer, 2018, p.59-60)

O fato é que no escopo extenso das estratégias de manipulação e mutação comportamental, assim como de manutenção da atenção dos usuários, pela vigilância permanente, pelo controle e pelo julgamento, as narrativas desinformacionais terminaram sendo beneficiadas pelos algoritmos que se guiam para os modelos de negócios das gigantes virtuais que trabalham em seu próprio benefício, e para tanto, também necessitam atender aos anseios de seus anunciantes, em uma visada ética bem complexa.

Nesse contexto, a desinformação favorece a monetização e a lucratividade das plataformas digitais, ao tempo em que beneficiam seus produtores com audiência e visibilidade e em muitos casos com lucratividade que tanto pode ser econômica, como acontece em inúmeros sites, canais e perfis que tratam de negacionismos históricos e científicos.

Atenção e desinformação se aliam na conformação da vigilância, do controle e do julgamento.

\section{CONSIDERAÇÕES FINAIS: ENTRE A DESINFORMAÇÃO E RESISTÊNCIA}

Em suma, percebemos até aqui que o fenômeno ao qual nos referimos é muito mais complexo que as simples fake news com as quais nos deparamos diariamente. Compõe um escopo que recebe informações de um sistema de vigilância, controle e julgamentos permanentes, e está sempre preparado para atuar dentro de uma economia da atenção, através dos inúmeros mecanismos de manutenção do foco dos usuários em suas redes e produtos específicos, assim como nos produtos mercadológicos que pagam pela nossa atenção. Agora transformada em produto muito bem avaliado no mercado virtual. 
Por outro lado, vale pensar na máxima exposta em 0 dilema das redes, ou seja, se você não é anunciante, se você não está pagando, você é o produto. Um produto que se coloca como cobaia para experimentos que possam mantê-lo dentro de um vício recorrente de conexão permanente, visados pelos sistemas de vigilância, controle e mecanismos de atenção, que é a conexão ininterrupta. A desconexão gera prejuízos para a rede, visto que seu modelo de monetização é baseado na visibilidade que vende e assegura o sucesso a seus anunciantes.

De acordo com o Instituto de Tecnologia de Massachusetts em pesquisa divulgada em 2018, as narrativas desinformacionais possuem alcance infinitamente maior dentro das redes sociais, podendo alcançar um número seis vezes superior ao de uma de notícia diária. Esses dados são confirmados de modo informal ao longo do documentário aqui já mencionado, quando os ex-profissionais de várias gigantes tecnológicas e que abrangem Google, Facebook, Instagram, Twitter, dentre outras, declaram que o modelo de negócios distribui algoritmos que supervalorizam a desinformação em detrimento da informação, tendo em vista o potencial da primeira para a lucratividade dos clientes anunciantes e das próprias plataformas.

Nesse contexto, se a desinformação $0^{3}$ enquanto produto é formatada com a intencionalidade de manipular em favor de interesses políticos que, em suma e no escopo geral acima descrito, é também mercadológico, por outro lado ela também é uma estratégia, portanto, vale pensar em modos de combatê-la em meio a esse cenário complexo e desfavorável.

Mas a desinformação é ainda e, principalmente, um fenômeno que tem, em sua vertente mercadológica, um braço; entretanto, também se estrutura por outras vias, nem sempre intencionais, contudo, enquanto componente da essência da informação, como seu outro lado, termina por se estruturar no contexto social como um fenômeno de grandes dimensões que tem provocado situações complexas, prejuízos e até comprometido a saúde das populações.

Nesse cenário desolador, temos presenciado o nascer de inúmeras iniciativas em todo o mundo que se estruturam em torno da construção de informações responsáveis e confiáveis e que extrapolam o campo da comunicação, mas se localizam em inúmeros campos do conhecimento, assim como estão dentro das Universidades, sobretudo nas públicas, mas também nas privadas e confessionais, e ainda estão no mercado, nas instituições do terceiro setor/sociedade civil e congregam pesquisadores, cientistas, jornalistas, filósofos, médicos, farmacêuticos, historiadores, antropólogos, dentre inúmeros outros profissionais que poderíamos mencionar aqui.

Foi, portanto, dentro de uma conjuntura de grande potencialização da produção e circulação de narrativas desinformacionais durante a pandemia da Covid-19, quando segundo a Organização das Nações Unidas (ONU), a Organização das Nações Unidas para a Educação, a Ciência e a Cultura (Unesco) e a Organização Mundial de Saúde (OMS), o fenômeno da desinformação se tornou também uma pandemia, que procuramos criar uma organização virtual informal sem fins lucrativos que denominamos de Rede Nacional de Combate à Desinformação (RNCD), lançada no final de setembro de 2020 e que, após um mês de seu lançamento, já congrega mais 70 parceiros entre instituições, coletivos, redes, projetos de divulgação científica, projetos de comunicação educativa, projetos de fact-checking, projetos sociais, observatórios, projetos de inteligência artificial, aplicativos de denúncia de fake news, laboratórios, núcleos de pesquisa, museus, dentre outros. A nossa intenção foi somar forças com vistas a compor uma onda sinérgica e positiva que possa confrontar, aos poucos, o mar que conforma o fenômeno desinformacional.

A nosso ver a resistência passa, sobretudo, pela capacidade de compreensão do outro e do seu despertar para a criticidade a partir do desenvolvimento de uma consciência histórica numa visada de Ricoeur (2010). Esse encontro, no entanto, pressupõe uma abertura para o diálogo que pode se dar a partir de uma escuta atenta aos anseios da população, sendo que tal escuta pode revelar ainda seus valores e crenças, a partir dos quais podemos promover um encontro, despertando afetividades possíveis e sociabilidades mais amplas.

3 Wardle e Derakhshan (2019) trabalham o que denominam de caos desinformacional a partir dos conceitos de misinformation, disinformation e mal-information. 


\section{REFERÊNCIAS}

ABRAMOVAY, Ricardo. A sociedade da vigilância em rede. Revista Quatro Cinco Um, São Paulo. Disponível em: http:// ricardoabramovay.com/sociedade-da-vigilancia-em-rede/. Acesso em: 10 out 2020.

ARENDT, Hannah. A vida do espírito. Rio de Janeiro: Civilização Brasileira, 2016

BAUDRILLARD, Jean. Simulacros e simulação. Lisboa: Relógio d'água, 2014.

BENTHAM, Jeremy. O panóptico. Belo Horizonte: Autêntica, 2019.

BOURDIEU, Pierre. A distinção: a crítica social do julgamento. São Paulo: Edusp, 2008.

BRUNO, Fernanda. Monitoramento, classificação e controle nos dispositivos de vigilância digital. In: ANTOUN, Henrique (org.). Web 2.0: participação e vigilância na era da comunicação distribuída. Rio de Janeiro: Mauad X, 2008. p.167-182.

DELEUZE, Gilles. Post-scriptum sobre as sociedades de controle. In: DELEUZE, Gilles. Conversações. Rio de Janeiro: Ed. 34 , 1992. p.219-226.

DELEUZE, Gilles. Pourparlers. Paris: Les Éditions de Minuit, 1990.

FOER, Franklin. O mundo que não pensa. Rio de Janeiro: LeYa, 2018.

FOUCAULT, Michel. História da sexualidade 1: a vontade de saber. Rio de Janeiro: Edições Graal, 1999.

FOUCAULT, Michel. Vigiar e punir. Petrópolis: Vozes, 2002.

HAMEL, Gary; PRAHALAD, Coimbatore Krishnarao. Competindo pelo futuro. Rio de Janeiro: Campus, 1995.

MATRIX. Direção: Lily Wachowski e Lana Wachowski. Estados Unidos: Warner Bros, 1999.

O DILEMA das redes. Direção: Jeff Orlwoski. Estados Unidos: Netflix, 2020

POSETTI, Julie; BONTCHEVA, Kalina. Desinfopandemic: deciphering Covid-19 disinformation. Paris: Unesco, 2020. Disponível em: https://en.unesco.org/sites/default/files/disinfodemic_deciphering_covid19_disinformation.pdf. Acesso em: 28 maio 2020.

RÊGO, Ana Regina; LEAL, Ranielle. Negação, verdade e desinformação: ubi véritas?, São Paulo [2020?]. No prelo.

RÊGO, Ana Regina; BARBOSA, Marialva. A construção intencional da ignorância: o mercado das informações falsas. Rio de Janeiro: Maud X, 2020.

RICOEUR, Paul. Tempo e narrativa. São Paulo: Martins Fontes, 2010.

SIMON, Hebert. Rational decision making in business organization. American Economic Review, Pittsburgh, v.69, p.493-513, 1979. 
SODRÉ, Muniz. Antropológica do espelho. Petrópolis: Vozes, 2002.

WARDLE, Claire; DERAKHSHAN, Hossein. Reflexão sobre a "desordem da informação": formatos da informação incorreta, desinformação e má-informação. In: IRETON, Cherilyn; POSETTI, Julia. Jornalismo, fake news \& desinformação. Paris: Unesco, 2019. p. 46-58. Disponível em: https://unesdoc.unesco.org/ark:/48223/ pf0000368647?fbclid=IwAR1ltj8iF00MPv69h0x4WViYAHzMUlp8VoYlTOMepi_TYL_utbV5xlgnnEk. Acesso em: 15 jul. 2020.

Artigo recebido em 08.01.2021 e aprovado em 12.01.2021 